\title{
The impact of informal cancer caregiving: A literature review on psychophysiological studies
}

\author{
Ricardo João Teixeira ${ }^{1,2,3}$ \\ Sónia Remondes-Costa ${ }^{4}$ | M. Graça Pereira ${ }^{1}$ \\ Tânia Brandão 5
}

\author{
${ }^{1}$ School of Psychology, University of Minho, \\ Braga, Portugal \\ ${ }^{2}$ Psychotherapy Department, Clínica da \\ Ordem, Porto, Portugal \\ ${ }^{3}$ Institute of Research and Advanced \\ Training in Health Sciences and \\ Technologies, CESPU, Gandra, Portugal \\ ${ }^{4}$ University of Trás-os-Montes and Alto \\ Douro, Vila Real, Portugal \\ ${ }^{5}$ Departamento de Psicologia, Centro \\ de Investigação em Psicologia (CIP- \\ UAL), Universidade Autónoma de Lisboa Luís \\ de Camões, Lisboa, Portugal \\ Correspondence \\ Ricardo João Teixeira, School of Psychology, \\ University of Minho, Campus de Gualtar \\ Braga, Portugal. \\ Email: ricardojft@gmail.com
}

\begin{abstract}
Caregiving can be experienced as a stressful process, which can cause psychological and physical consequences. The combination of prolonged stress and the physical demands of caregiving may impair the physiological functioning of caregivers and increase the risk of health problems creating considerable stress in the life of caregivers regarding emotional, physical, social and financial areas. This literature review explored studies that used measures of the autonomic nervous system in caregivers of oncology patients such as electrodermal and cardiovascular (re)activity. The results revealed that caregivers had elevated stress levels and a serious autonomic imbalance that may, in the long term, trigger negative health consequences such as infectious diseases, cancer progression, cardiovascular disease and even premature death. The results showed the need to carry out preventive strategies in this population, in order to improve the autonomic profile of caregivers of cancer patients.
\end{abstract}

KEYWORDS

autonomic nervous system, cancer, informal caregivers, peripheral measures

\section{1 | INTRODUCTION}

Since pre-historic times, the provision of informal care has been the main source of protection for individuals dealing with health problems (Lebel et al., 2001). Although caregivers have always had a socio-economic value to society, in the future they will be even more important due to the growing number of elderly and the high prevalence of chronic diseases (Shilling, Matthews, Jenkins, \& Fallowfield, 2016). The act of caring is based on personal and cultural values that give meaning to caregiving (Yamaguchi, Cohen, \& Uza, 2016). For this reason, it is not uncommon for caregivers to report positive experiences, such as more intimate relationships, more empathy with others and greater appreciation of life (Mosher, Adams, et al., 2017; Young \& Snowden, 2017). However, caring for a family member with cancer is a challenging experience that requires an adjustment to change (Teskereci \& Kulakac, 2018), adaptation to daily care tasks and to a new lifestyle (Ellis et al., 2017). Moreover, they usually need to establish a relationship and communicate with health professionals (Oh, 2017), understand medical information (Mosher, Ott, Hanna, Jalal, \& Champion, 2017) and, in cases of advanced cancer, suffer with the imminent loss of the loved one (Kuo et al., 2017).

Caregiving can be a stressful experience, with potentially negative consequences on both psychological and physical levels. In terms of psychological outcomes, several reviews and meta-analyses showed a higher prevalence of psychiatric disorders, particularly disorders of anxiety and depression, in caregivers, when compared to controls (Cochrane, Goering, \& Rogers, 2007; Pruchno \& Potashnik, 1989; Schulz, O'Brien, Bookwala, \& Fleissner, 1995). In fact, compared to other contexts of care, the caregiving process in the oncology context presents distinct features. Despite the variability in the available studies in terms of caregivers' and patients' characteristics, cancer caregivers are usually younger and provide care for shorter periods of time (but in an intense way) and care for patients with a wide variety of physical and emotional symptoms as a consequence 
of multimodal therapies (Kent et al., 2016). For all of these reasons, the provision of care in oncology can create considerable stress in the lives of caregivers, affecting caregivers' physical health, immune function, health behaviours, mental health, social activities and relationships, finances and work (Lambert, Levesque, \& Girgis, 2016). In the context of terminal illness, caregivers face the dual challenge of providing care and having to deal with anticipatory grief.

At a physiological level, research also suggests that the combination of prolonged stress and the physical demands of caregiving may impair the physiological functioning of caregivers and increase the risk of health problems (Kiecolt-Glaser, Glaser, Gravenstein, Malarkey, \& Sheridan, 1996; Schulz et al., 1997). Therefore, caregiving can be considered a risk factor for impairing physical health, since it can trigger a cascade of stress responses through the activation of the hypothalamic-pituitary-adrenal and the sympathetic adrenal-medullary axes involving hormonal, immune, cardiovascular and metabolic disorders (Grant, 1999; Vitaliano et al., 2002).

Some studies have shown that caregivers tend to present a higher cardiovascular reactivity (Lee, Colditz, Berkman, \& Kawachi, 2003; Mausbach, Patterson, Rabinowitz, Grant, \& Schulz, 2007). Also, caregivers tend to have a poorer immune response compared to non-caregivers that is not caused by nutritional factors, sleep or other health problems (Kiecolt-Glaser et al., 1996). Moreover, in the presence of mental or emotional strain, caregiving has been associated with an increased mortality risk (63\% higher in comparison with non-caregiving controls; Schulz \& Beach, 1999). In addition, caregivers are much less likely to have time to rest when they are ill, time to practice exercise or to get adequate sleep (Burton, Newsom, Schulz, Hirsch, \& German, 1997).

The study of physical outcomes in the provision of informal care is limited essentially to the physiological functioning of caregivers of elderly and/or people with dementia (Etters, Goodall, \& Harrison, 2008; Pinquart \& Sörensen, 2003; Vitaliano, Zhang, \& Scanlan, 2003). In a literature review carried out by Schulz, Visintainer, and Williamson (1990), only 11 of the 34 studies reviewed were focused on the physical health of the caregiver, and only one study included physiological measures. In other reviews that included 40 studies (Schulz et al., 1995), researchers found that caregivers had more chronic diseases and drug consumption than non-caregivers although other studies found no differences on these outcomes. These results highlighted the need of using physiological measures in the study of care providers. According to Vitaliano et al. (2003), physiological measures can certainly help to explain the associations between care and disease. Indeed, the physiological measures may show associations with the caregiver's experiences much earlier than chronic diseases.

Psychophysiology opened the doors for a deeper understanding and explanation of some human phenomena. Based on the organisation of the nervous system, psychophysiological techniques may be divided into three broad categories (Stern, Ray, \& Quigley, 2001): (a) those dealing with the activity of the central nervous system, such as electroencephalography, the evoked potentials, the electrical activity of the brain, the location of the source dipole and based imaging methods (e.g., positron emission tomography, functional magnetic resonance imaging of the brain and regional cerebral blood flow); (b) those measuring the activity of the somatic nervous system, such as electromyography, electro-oculogram and the measurements of respiratory activity; and (c) those measuring the activity of the autonomic nervous system, which includes techniques such as electrodermal activity, electrocardiography, plethysmography and electrogastrography.

Considering the objectives of this paper, the measures that will be explored in more detail are two measures of the autonomic nervous system namely the electrodermal activity (skin conductance) and the cardiovascular activity (mainly heart rhythm). The electrodermal activity (EDA) is an important indicator of the activation of the autonomic nervous system (Dawson, Schell, \& Filion, 2017), being sensitive to events with high emotional and cognitive impact (Sequeira, Hot, Silvert, \& Delplanque, 2009). Specifically, skin conductance (SC) is highly associated with the activity of the sympathetic nervous system (Arangüena \& Dorado, 2000), and it is a particularly useful measure in the evaluation of emotional reactivity (Orr \& Kaloupek, 1997). Heart rate (HR) and blood pressure (BP) are two cardiovascular measures commonly used in psychophysiology (Berntson, Quigley, Norman, \& Lozano, 2017; Orr \& Kaloupek, 1997). Cardiovascular activity (CA) differs according to psychological aspects due to emotional changes, and it is therefore an important autonomic physiological variable (Arangüena \& Dorado, 2000). An increasing body of evidence suggests that excessive cardiovascular reactivity to mental stress is a risk factor for the development of coronary artery disease and hypertension (Blascovich \& Katkin, 1993; Treiber et al., 2003).

Electrodermal reactivity and cardiovascular reactivity have been recognised as being associated with atherosclerosis, hypertension and other cardiovascular and immune disorders (Cacioppo et al., 1995; Jennings et al., 2004; Kronholm, Hyyppä, Jula, \& Toikka, 1996; Matthews, Salomon, Brady, \& Allen, 2003; Powell et al., 2013). The use of these two measures has spread also due to their non-invasive characteristics and reduced cost when compared to measures of the central nervous system. In addition, these peripheral measures have the advantage of avoiding some of the common problems in the interpretation of the results obtained, presented in other complex techniques of measurement of the central nervous system.

Having as background some of the principles, methods and practices of psychophysiology, this paper addresses the psychobiological stressors associated with the provision of care in caregivers of patients with cancer. Specifically, in this review we aimed to summarise the available evidence regarding the psychophysiological functioning (in terms of electrodermal and cardiovascular activity) among caregivers of patients with cancer in order to improve our knowledge regarding potential psychophysiological pathways through which cancer caregiving influences caregivers' illness outcomes.

\section{2 | METHOD}

\section{1 | Eligibility criteria}

Full-text research articles published in English or Portuguese that included at least one measure to assess psychophysiological 
functioning (in terms of electrodermal and cardiovascular activity) in adult caregivers of patients with cancer were eligible. Quantitative, qualitative, mixed-method studies and reviews were eligible. Studies assessing other indicators of psychophysiological functioning (other than electrodermal and cardiovascular activity) and case-control or intervention studies (i.e., studies evaluating psychophysiological functioning after participation in a psychosocial intervention) were excluded.

\section{2 | Search strategy}

Database searches were conducted for articles published from inception up to 2018 in MEDLINE, CINAHL, ERIC and Psychology \& Behavioral Sciences Collection. Searches in these databases were supplemented by additional manual searching in Google. The key search terms used were as follows: "cancer," "oncology," "caregiver," "caregiving," "career," "physiology" and "psychophysiology." Titles and abstracts were assessed for eligibility by one researcher. Doubts were discussed with other researchers.

\section{3 | RESULTS}

A total of 203 articles were identified. From these, 27 were excluded because they were duplicates and 169 because they were not relevant to the current review topic (see Figure 1).

The abstracts of the remaining seven studies were screened and evaluated. From these, two were excluded (one was an intervention study and one did not include indicators of psychophysiological functioning assessed in this review). A total of five studies exploring the psychophysiological responses associated with informal cancer caregiving were included in this review. All studies examined cardiovascular reactivity (namely blood pressure and heart rate), and only one study examined electrodermal reactivity. Along with these measures, studies explored also psychological outcomes. Two studies explored the link between psychophysiological functioning and depression; anxiety, family functioning, perceptions of stress, quality of life, burden and post-traumatic stress disorder symptoms were also explored.

Since few studies were found, results from included studies were also related to studies from other caregiving contexts and from the broad psychophysiological literature to better understand the results. Results were divided into two groups: one focused on electrodermal (re)activity and another focused on cardiovascular (re)activity. The following information was extracted: author/study period, study objectives, participants, design/type of study, measure used to assess psychophysiological responses, variables associated, statistical analysis and main findings (see Table 1).

\subsection{Electrodermal (re)activity in caregivers}

Research studies exploring the EDA of cancer caregivers are extremely scarce. Only one cross-sectional experimental study conducted with caregivers of cancer patients was found (Teixeira \& Pereira, 2014). In this study, psychological as well as psychophysiological measures were collected in order to explore differences on these measures among cancer caregiving and controls (controls included adult children without a chronically ill parent recruited at
FIGURE 1 Flowchart of literature search

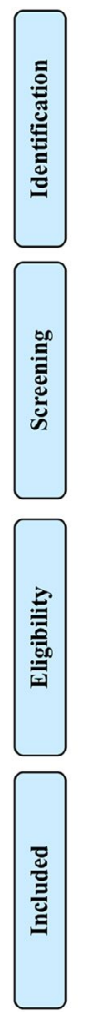

Records identified through database searching $(n=202)$
Additional records identified through other sources $(n=1)$

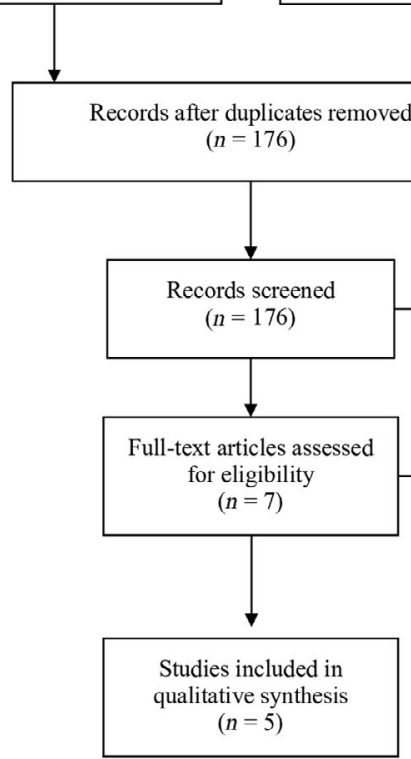

Records excluded $(n=169)$ Not relevant to the current review $(n=169)$

Full-text articles excluded, with reasons $(n=2)$

Assess other indicators of psychophysiological functioning $(n=1)$ $\operatorname{RCT}(n=1)$ 

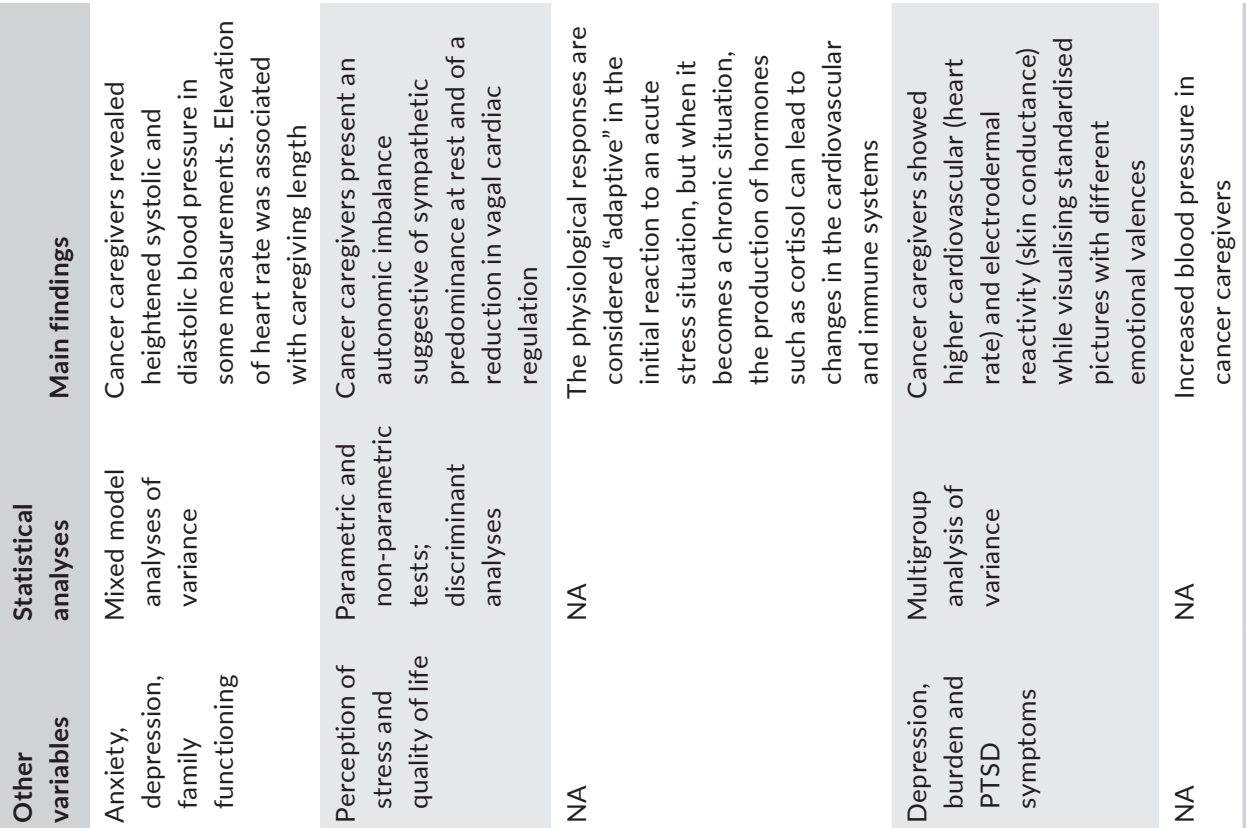

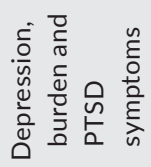
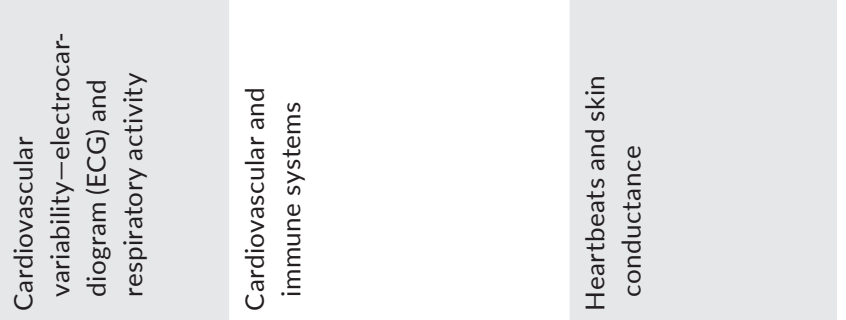

z

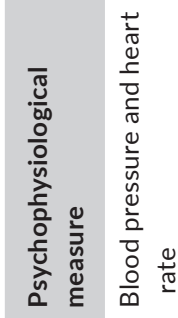

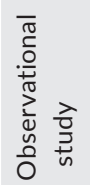

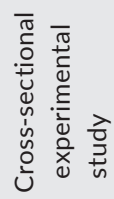

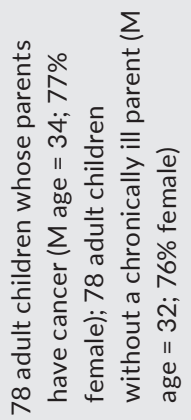

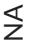

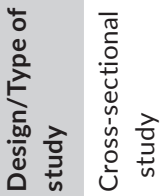

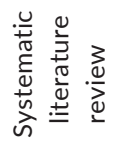

$\frac{3}{\stackrel{3}{\Psi}}$

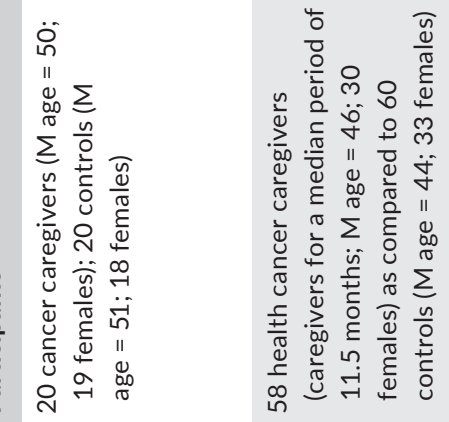

$\varangle$

$\varangle$

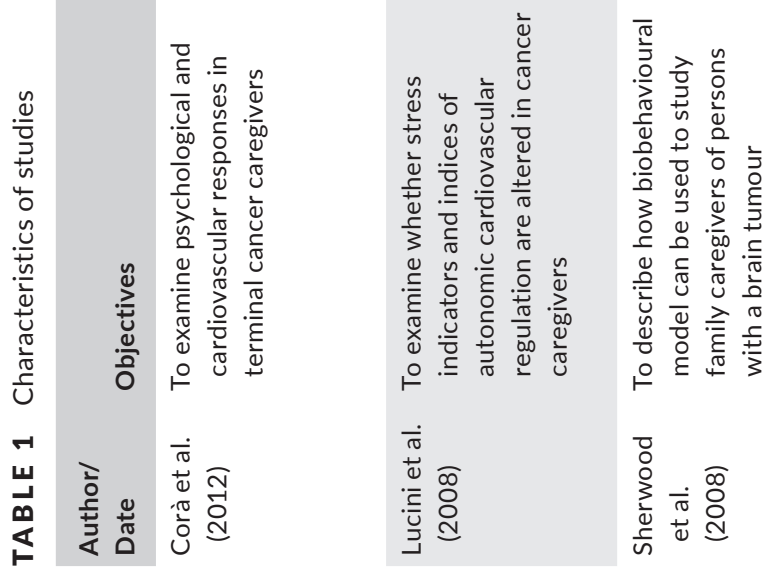

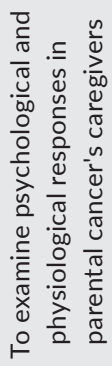
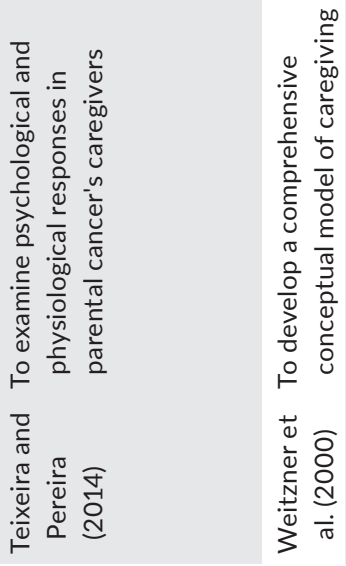
a university). Two matched groups, with 78 participants each (parental cancer vs. control), were used. EDA and cardiovascular (presented later) responses were recorded after picture visualisation. Physiological data were collected using the Physiolab software, and the visual stimuli used were drawn from the International Affective Picture System. The authors found significant differences on skin conductance for all types of pictures. Specifically, the parental cancer group presented a higher skin conductance suggesting a higher arousal for this group, confirming the initial hypotheses that there were differences among the two groups in terms of psychophysiological reactivity.

Other studies with care providers within other contexts may be taken as a focus of interest. For example, although this is not a "typical" study with care providers, Stampler, Wall, Cassisi, and Davis (1997) conducted a research on the premise that spouses may inadvertently contribute to the maintenance of the patient's pain behaviours. Based on existing literature, the authors hypothesised that individuals respond with physiological arousal when they see others in pain and that the magnitude of these responses in spouses of patients with pain varies according to their level of marital satisfaction. To this end, the researchers collected data from 26 couples, in which one of the partners suffered from chronic low back pain. The authors examined marital satisfaction and care of the spouse (in terms of physiological responses) during marital interactions regarding the topic "pain." The strengthening of the pain behaviour by the spouse was named "solicitude" that, in turn, seemed to have an impact on marital satisfaction. At the level of SC, the study showed that spouses less satisfied with their marital relationship showed higher SC in comparison with spouses more satisfied with it (Stampler et al., 1997).

Thompson et al. (2004) conducted a comparative study in terms of gender and emotional and biological responses of the caregiver spouses of patients with Alzheimer in terms of psychosocial, physiological and immunophenotypic parameters. Male spouses' caregivers showed significantly lower levels of stress, depression, subjective burden, anxiety, anger-hostility and somatic symptoms, as well as higher levels of mental health, sense of coherence, number of NK cells and better physical and social functioning. In turn, the wife's caregivers showed higher counts of T-helper cells (Th) and less NK cells than husbands' caregivers. Finally, men showed a less intense physiological response to stress, particularly at the HR level and skin temperature. However, at the level of changes in SC, significant differences between men and women were found, although men reported "feeling" more relaxed than women.

Lewis, Escamilla, and Novian (2008) conducted a study with cultural and gender implications on emotional responses of Mexican American family caregivers of patients with Alzheimer compared to Caucasians caregivers (male and female) in terms of psychosocial, physiological and immunological variables. Caucasian male caregivers showed better outcomes in positive psychosocial health indicators (i.e., quality of life, sense of coherence, general health, social functioning and vitality) and lower results in negative indicators (i.e., stress, anxiety, depression, somatisation and subjective burden). As for the physiological and immune measures, the results remained with Caucasians caregivers presenting a higher percentage of NK cells, and a smaller SC, before a cognitive stimulation.

More recently, Moya-Albiol et al. (2011) studied the reactivity to stress, in the laboratory, analysing SC in caregivers (parents) of people with autism spectrum disorders, based on the assumption that these individuals may show a different physiological response due to their specific situation, characterised by a continuous state of alert. To such purposes, the authors compared a group of 44 caregivers (i.e., parents of children with autism spectrum disorders) and 42 controls (i.e., parents of children without autism spectrum disorders) in performing a set of different mental tasks. They continuously recorded two indices of the SC: response and level. The results showed that caregivers showed a lower EDA reactivity to mental stress, when compared to controls, with a stronger effect for men. Although controversial, these results may reflect a lower reactivity to stressful situations from caregivers and, consequently, the loss of a potential adaptive stress response in this population. The authors concluded that the results reflected an idiosyncratic emotional situation of caregivers of individuals with an autistic spectrum disorder due to the special conditions they were subjected to (e.g., concerns about the future of their children and characteristics of the care, including number of hours providing care and caregiving being shared or not).

\subsection{Cardiovascular (re)activity in caregivers}

The association between psychological morbidity and CA in adult children of cancer patients has received few attention from the investigation. Lucini et al. (2008) conducted an observational study aiming to explore whether stress indicators and indices of CA would be altered in cancer caregivers. The study included 58 cancer caregivers and 60 matched controls (i.e., healthy volunteers, who denied any kind of stressful condition). Blood pressure, electrocardiogram (ECG) and respiratory activity were recorded using a wireless radiotelemetry system and Finapres device. The results showed an increase in cardiac activity sympathetically. It is important to note that these caregivers were assessed at the early stage of the disease, suggesting that caregiving may have a fast psychophysiological impact.

In the literature review performed by Sherwood et al. (2008), few studies examining the interaction between the biobehavioural responses to stress and the caregiving were found. For these authors, the physiological responses are considered "adaptive" in the initial reaction to an acute stress situation (e.g., a diagnosis of primary malignant brain tumour and their initial treatments). However, when it becomes a chronic situation (e.g., due to factors such as the prolonged treatment and disease progression), the production of hormones such as the cortisol can lead to changes in the cardiovascular and immune systems, compromising the overall physical health status of the individual. In this sense, the most frequent changes in the cardiovascular system were associated with an increased 
peripheral and vascular resistance hypertension. Weitzner, Haley, and Chen (2000) also found in their review that caregivers of older cancer patients usually reported an increase in BP associated with complex experiences in caregivers of cancer patients, in a context of constant concern, loss, grief, conflict, guilt and resentment, leading to an enhanced state of psychological morbidity.

More recently, the study of Corà, Partinico, Munafò, and Palomba (2012) aimed to examine psychological and cardiovascular responses in terminal cancer caregivers. Psychological variables (depression and mood disorders, anxiety and anger) and CA (i.e., cardiovascular risk, blood pressure and heart rate) were assessed in 20 caregivers and compared with matched control group (healthy individuals similar in age and sex). Physiological measures were assessed using a validated automatic BP device at rest over 2 weeks (in order to deal with BP and HR variability). As expected, cancer caregivers reported higher levels of depression, state anxiety and more sleep dysfunctions in comparison with controls. They also experienced heightened systolic and diastolic blood pressure. In this study, elevation of HR was associated with a longer duration of care. Although in this study BP and HR have been recorded at rest conditions, some extensive literature indicates that these parameters at rest, although not clinically relevant, are important cardiovascular risk precursors (Cook, Togni, Schaub, Wenaweser, \& Hess, 2006; Cooney et al., 2010; Fox et al., 2007; Gu, Burt, Paulose-Ram, Yoon, \& Gillum, 2008; Palatini, 2009; Palatini \& Julius, 1997). Finally, Teixeira and Pereira (2014) with a sample of 78 cancer caregivers found that this group of caregivers showed higher CA (in terms of $H R$ ) while visualising standardised pictures with different emotional valences.

A high risk of cardiovascular disorders can be associated with sleep disorders (Mausbach et al., 2007; McCurry, Logsdon, Teri, \& Vitiello, 2007) and can be modulated by the emotional state of the caregiver, the quality of the relationship between the caregiver and the receiver of care, the requirements of the care and the perception of social support (Shaw et al., 2003; Uchino, Kiecolt-Glaser, \& Cacioppo, 1992). Hypertensive caregivers also express an increased cardiovascular reactivity (BP and HR) before acute stressors (Vitaliano, Russo, Bailey, Young, \& McCann, 1993).

Shaw et al. (1999), using a longitudinal design, evaluated the stress response in 144 spouses/caregivers of patients with Alzheimer's disease and a control group of 47 participants (i.e., demographically equivalent non-caregiving controls), in order to understand whether belonging to the first group increased the probability of exceeding BP (at the beginning of the study, 33\% of caregivers and $30 \%$ of controls were receiving antihypertensive treatment). Systolic and diastolic BP was assessed every 6 months during 2-6 years, so that researchers could determine in which group there was an increased risk of developing hypertension. Additionally, the authors intended to determine whether this increased risk was linked to variables such as the extent of assistance provided, patient problem behaviours or caregiver distress. The results showed that the risk of reaching borderline hypertension values was higher in caregivers than in the control group.
Later, the same team conducted a new longitudinal study over 7 years, where they semiannually recorded the BP levels in a sample of 111 caregivers of spouses of Alzheimer patients. Furthermore, they evaluated the requirements of care, emotional expressiveness, social desirability and hostility. The results showed that the risk of developing hypertension, in older caregivers, was linked to the perceived stress (intensified when they had to handle more dementia behaviour and difficulties in carrying out daily activities) and to a lower emotional expression (Shaw et al., 2003).

Other authors have attempted to study the apparent relationship between cardiovascular comorbidity and the caregiver function of a family member with a chronic illness. Von Känel et al. (2006) studied this relationship through a high coagulation status (associated with the appearance of thrombosis) of blood as a physiological response to chronic stressors resulting from providing care for a family with Alzheimer's disease. The sample consisted of 54 spouses, and beyond the physiological assessment associated with a pro-coagulant, the authors conducted a structured interview to identify stress factors not related to the act of caring. The results showed that the daily stress, combined with the chronic stress of providing care to a family with Alzheimer's disease, might cause a state of hypercoagulability, contributing to an increased likelihood of coronary heart disease and mortality in this population.

Mausbach et al. (2005) found that depressive symptoms may exaggerate the adrenergic response (elevated baseline plasma levels of noradrenaline) in caregivers of patients with Alzheimer's, possibly leading to an allostatic load (McEwen, 2006). This could lead to a predisposition to negative health consequences, including cardiovascular morbidity.

Some researches have also focused on possible differences in terms of physiological reactivity, considering the variable "race." For example, Knight and McCallum (1998) evaluated the cardiovascular reactivity to stress and indicators of depression, anxiety and two positive assessment measures on tension, in 110 Caucasian caregivers and 44 African Americans caregivers. The latest have generally revealed a higher use of positive revaluations. Both groups showed an increased cardiac reactivity in a cognitive task related to the variable "history of care." In the Caucasian sample, the researchers found a positive association between depression and cardiac reactivity, in both stress-inducing situations. However, in the African American sample, this relationship was reversed in the variable "history of care," leading researchers to conclude that there were cultural differences between caregivers, affecting the emotional and physical reactions to stressful situations. More recently, Wilcox, Bopp, Wilson, Fulk, and Hand (2005) also examined this variable in a sample of 28 women (16 Caucasian and 12 African American) caregivers of a family member with dementia, in order to search for psychosocial and psychophysiological differences, considering the caregivers' race. The results showed a greater cardiac reactivity in African American caregivers as well as higher levels of salivary cortisol and psychological distress, than in the Caucasian caregivers.

Schrag, Hovris, Morley, Quinn, and Jahanshahi (2006) studied the effect of caregiving in family members of patients with Parkinson in 
terms of physical and mental health. In a sample of 123 caregivers, they assessed depressive symptoms and factors associated with the burden. At the same time, BP values were also measured. The results indicated that $40 \%$ of caregivers ( $66 \%$ females) exhibited health changes (hypertension), as well as increased levels of depression and impairment of social life.

In another context, Soares (2009) investigated psychosocial variables and physiological reactivity in 120 caregivers of drug addicts and 36 controls (i.e., healthy non-caregivers), using visual stimuli with emotional content. The main results in physiological variables showed lower levels of HR in caregivers without burden. Caregivers with post-traumatic stress disorder (PTSD) showed higher levels of cortisol. In turn, the duration of caregiving (>17 years) was associated with higher levels of HR and cortisol. However, the results for $\mathrm{SC}$ were not significant.

\section{4 | DISCUSSION}

The aim of this review was to summarise the available evidence about the psychophysiological functioning of caregivers of patients with cancer. Overall, the results of this review suggest that cancer caregivers, in comparison with controls, present higher electrodermal and cardiovascular reactivity (Corà et al., 2012; Lucini et al., 2008; Teixeira \& Pereira, 2014). While few studies have been included in this review, this pattern of results is in line with previous research conducted with caregivers outside of the cancer context (Moya-Albiol et al., 2011).

Moreover, results seem to suggest that cancer caregiving may have detrimental consequences for the psychophysiological functioning not only during long-term care (Corà et al., 2012; Shaw et al., 1999) but also during short periods of care. Indeed, in the Lucini et al. study (2008), caregivers of patients with cancer altered psychophysiological functioning in the early stage of the disease suggesting that caregiving may have a fast impact on psychophysiological functioning. However, Sherwood et al. (2008) highlight the "adaptive" nature of psychophysiological alterations during the initial reaction to an acute stress situation.

While the included studies did not control for the potential moderator or mediator role of socio-demographic and psychological variables on the link between caregiver stress and psychophysiological functioning, studies within other caregiving contexts (e.g., chronic pain or autism) suggested that gender (Moya-Albiol et al., 2011) or marital satisfaction (Stampler et al., 1997) may interfere with this link. These results seem to suggest that the impact of cancer caregiving on psychophysiological functioning may depend on contextual factors.

\section{1 | Conclusions, limitations and implications for practice and research}

Caring for sick family members is a physically and psychologically stressful task engendering stress that might compromise the emotional health and endorse multiple risks to the body. Different studies with family caregivers, from different clinical settings (cancer, Alzheimer, Parkinson, autism) have found, through physiological measures, that stress reactivity is associated with an increased electrodermal and cardiovascular activity, thus contributing to the increased risk of cardiovascular disease and immune suppression.

It is important to keep in mind, however, that this review has some limitations. First, the sample of this review is small since only five studies were included and the design of the studies varied greatly. This evidences that the physiological impact of cancer caregiving remains understudied. Most studies were cross-sectional or reviews. For these reasons, caution is needed in interpreting results since causality cannot be derived. While all of the quantitative studies used a control group, they included small sample sizes, which limit our conclusions. Moreover, one of the studies employed an experimental task to examine physiological functioning among cancer caregivers, which means that this physiological functioning may not be true in a non-experimental environment. Second, only English and Portuguese published studies were included. This may lead to some reporting biases since some relevant studies may be missed because they were not published or were not present in traditional outlets.

Despite these limitations, this review provides important research implications. First, it suggests that more studies are needed to examine the physiological impact of cancer caregiving since we only found five studies. Second, because studies suggest a heightened electrodermal and cardiovascular activity within this context, future studies should further explore not only these indicators, but also other physiological indicators (e.g., respiratory activity, temperature or neuronal activity). Also, longitudinal studies should be conducted in order to explore changes over time in the process of adaptation to the caregiving task and the long-term impact of caregiving-related physiological changes for the physical health of caregivers.

Also, important clinical implications are identified to improve the care provided to family caregivers as second-order patients who also need and deserve care. While more studies are needed, findings suggest that cancer caregivers are at increased risk of physiological changes and, consequently, have a higher risk of developing chronic diseases and/or have their immune system functioning compromised. Thus, this paper shows how important is for health professionals to address the psychosocial needs of family caregivers to reduce caregivers' burden, prevent physical and mental illness, and improve their quality of life.

For these reasons, psychological and psychophysiological symptoms should be screened as part of the routine care provided by healthcare professionals. Moreover, from a prevention point of view, psychosocial support should be provided to cancer caregivers in an early phase of the caregiving process in order to avoid the development of psychophysiological symptoms. Gender performs an important role on caregiving, with females being more vulnerable to stress. This confirmation has also important clinical implications, so that female caregivers can warrant even greater attention from health professionals. Interventions should therefore be gender-specific, 
such as self-help groups or psycho-educational stress management groups for female caregivers.

Finally, physiological variables in the context of other chronic illnesses should be explored targeting not only patients and caregivers, but also health professionals, particularly those with higher levels of burnout. From a heuristic point of view, this type of investigation would have important practical implications, regarding the design of interventions that could meet formal and informal caregivers' specific needs.

\section{ORCID}

Ricardo João Teixeira (iD https://orcid.org/0000-0003-3820-1660

M. Graça Pereira (iD https://orcid.org/0000-0001-7987-2562

Tânia Brandão (iD https://orcid.org/0000-0001-7865-2445

\section{REFERENCES}

Arangüena, L., \& Dorado, J. (2000). Psicofisiologia. Fundamentos metodológicos [Psychophysiology. Methodological foundations]. Madrid, Spain: Pirámide.

Berntson, G., Quigley, K., Norman, G., \& Lozano, D. (2017). Cardiovascular psychophysiology. In J. Cacioppo, L. Tassinary, \& G. Berntson (Eds.), Handbook of psychophysiology (pp. 183-216). Cambridge, UK: Cambridge University Press.

Blascovich, J., \& Katkin, E. S. (1993). Cardiovascular reactivity to psychological stress and disease: Conclusions. In J. Blascovich, \& E. S. Katkin (Eds.), Cardiovascular reactivity to psychological stress and disease (pp. 225-238). Washington, DC: American Psychological Association.

Burton, L. C., Newsom, J. T., Schulz, R., Hirsch, C. H., \& German, P. S. (1997). Preventive health behaviors among spousal caregivers. Preventive Medicine, 26(2), 162-169. https://doi.org/10.1006/ pmed.1996.0129

Cacioppo, J. T., Malarkey, W. B., Kiecolt-Glaser, J. K., Uchino, B. N., Sgoutas-Emch, S. A., Sheridan, J. F., ... Glaser, R. (1995). Heterogeneity in neuroendocrine and immune responses to brief psychological stressors as a function of autonomic cardiac activation. Psychosomatic Medicine, 57, 154-164. https://doi. org/10.1097/00006842-199503000-00008

Cochrane, J. J., Goering, P. N., \& Rogers, J. M. (2007). The mental health of informal caregivers in Ontario: An epidemiological survey. American Journal of Public Health, 87(12), 2002-2007. https://doi.org/10.2105/ AJPH.87.12.2002

Cook, S., Togni, M., Schaub, M. C., Wenaweser, P., \& Hess, O. M. (2006). High heart rate: A cardiovascular risk factor? European Heart Journal, 27(20), 2387-2393.

Cooney, M. T., Vartiainen, E., Laakitainen, T., Juolevi, A., Dudina, A., \& Graham, I. M. (2010). Elevated resting heart rate is an independent risk factor for cardiovascular disease in healthy men and women. American Heart Journal, 159(6), 612-619. https://doi.org/10.1016/j. ahj.2009.12.029

Corà, A., Partinico, M., Munafò, M., \& Palomba, D. (2012). Health risk factors in caregivers of terminal cancer patients: A pilot study. Cancer Nursing, 35(1), 38-47. https://doi.org/10.1097/ NCC.0b013e31820d0c23

Dawson, M., Schell, A., \& Filion, D. (2017). The electrodermal system. In J. Cacioppo, L. Tassinary, \& G. Berntson (Eds.), Handbook of psychophysiology (pp. 217-243). Cambridge, UK: Cambridge University Press.
Ellis, K. R., Janevic, M. R., Kershaw, T., Caldwell, C. H., Janz, N. K., \& Northouse, L. (2017). Engagement in health-promoting behaviors and patient-caregiver interdependence in dyads facing advanced cancer: An exploratory study. Journal of Behavioral Medicine, 40(3), 506-519. https://doi.org/10.1007/s10865-016-9819-6

Etters, L., Goodall, D., \& Harrison, B. E. (2008). Caregiver burden among dementia patient caregivers: A review of the literature. Journal of the American Academy of Nurse Practitioners, 20(8), 423-428. https://doi. org/10.1111/j.1745-7599.2008.00342.x

Fox, K., Borer, J. S., Camm, A. J., Danchin, N., Ferrari, R., Lopez Sendon, J. L., ... Tendera, M. (2007). Resting heart rate in cardiovascular disease. Journal of the American College of Cardiology, 50(9), 823-830. https:// doi.org/10.1016/j.jacc.2007.04.079

Grant, I. (1999). Caregiving may be hazardous to your health. Psychosomatic Medicine, 61(4), 420-423. https://doi. org/10.1097/00006842-199907000-00002

Gu, Q., Burt, V. L., Paulose-Ram, R., Yoon, S., \& Gillum, R. F. (2008). High blood pressure and cardiovascular disease mortality risk among U.S. adults: The third National Health and Nutrition Examination Survey Mortality Follow-up Study. Annals of Epidemiology, 18(4), 302-309.

Jennings, J. R., Kamarck, T. W., Everson Rose, S. A., Kaplan, G. A., Manuck, S. B., \& Salonen, J. T. (2004). Exaggerated blood pressure responses during mental stress are prospectively related to enhanced carotid atherosclerosis in middle-aged Finnish men. Circulation, 110, 2198-2203. https://doi.org/10.1161/01. CIR.0000143840.77061.E9

Kent, E. E., Rowland, J. H., Northouse, L., Litzelman, K., Chou, W.-Y., Shelburne, N., ... Huss, K. (2016). Caring for caregivers and patients: Research and clinical priorities for informal cancer caregiving. Cancer, 122(13), 1987-1995. https://doi.org/10.1002/cncr.29939

Kiecolt-Glaser, J. K., Glaser, R., Gravenstein, S., Malarkey, W. B., \& Sheridan, J. (1996). Chronic stress alters the immune response to influenza virus vaccine in older adults. Proceedings of the National Academy of Sciences, USA, 93(7), 3043-3047. https://doi. org/10.1073/pnas.93.7.3043

Knight, B. G., \& McCallum, T. J. (1998). Heart rate reactivity and depression in African-American and white dementia caregivers: Reporting bias or positive coping? Aging \& Mental Health, 2(3), 212-221.

Kronholm, E., Hyyppä, M. T., Jula, A., \& Toikka, T. (1996). Electrodermal lability and hypertension. International Journal of Psychophysiology, 23, 129-136. https://doi.org/10.1016/0167-8760(96)00044-X

Kuo, S. C., Chou, W. C., Chen, J. S., Chang, W. C., Chiang, M. C., Hou, M. M., \& Tang, S. T. (2017). Longitudinal changes in and modifiable predictors of the prevalence of severe depressive symptoms for family caregivers of terminally ill cancer patients over the first two years of bereavement. Journal of Palliative Medicine, 20(1), 15-22. https://doi. org/10.1089/jpm.2016.0116

Lambert, S. D., Levesque, J. V., \& Girgis, A. (2016). The impact of cancer and chronic conditions on caregivers and family members. In B. Koczwara (Ed.), Cancer and chronic conditions (pp. 159-202). Singapore City, Singapore: Springer.

Lebel, S., Trinkaus, E., Faure, M., Fernandez, P., Guerin, C., Richter, D., ... Wagner, G. a. (2001). Comparative morphology and paleobiology of Middle Pleistocene human remains from the Bau de I'Aubesier, Vaucluse, France. Proceedings of the National Academy of Sciences USA, 98(20), 11097-11102. https://doi.org/10.1073/ pnas.181353998

Lee, S., Colditz, G. A., Berkman, L. F., \& Kawachi, I. (2003). Caregiving and risk of coronary heart disease in U.S. women: A prospective study. American Journal of Preventive Medicine, 24(2), 113-119.

Lewis, S. L., Escamilla, M., \& Novian, A. (2008). Comparison of emotional and biological parameters in Mexican American and white male and female caregivers of patients with Alzheimer's disease. Paper presented 
at the National State of the Science Congress on Nursing Research, Washington, DC.

Lucini, D., Cannone, V., Malacarne, M., Bruno, D., Beltrami, S., Pizzinelli, P., ... Pagani, M. (2008). Evidence of autonomic dysregulation in otherwise healthy cancer caregivers: A possible link with health hazard. European Journal of Cancer, 44(16), 2437-2443. https://doi. org/10.1016/j.ejca.2008.08.006

Matthews, K. A., Salomon, K., Brady, S. S., \& Allen, M. T. (2003). Cardiovascular reactivity to stress predicts future blood pressure in adolescence. Psychosomatic Medicine, 65, 410-415. https://doi. org/10.1097/01.PSY.0000057612.94797.5F

Mausbach, B. T., Dimsdale, J. E., Ziegler, M. G., Mills, P. J., Ancoli-Israel, S., Patterson, T. L., \& Grant, I. (2005). Depressive symptoms predict norepinephrine response to a psychological stressor task in Alzheimer's caregivers. Psychosomatic Medicine, 67(4), 638-642. https://doi. org/10.1097/01.psy.0000173312.90148.97

Mausbach, B. T., Patterson, T. L., Rabinowitz, Y. G., Grant, I., \& Schulz, R. (2007). Depression and distress predict time to cardiovascular disease in dementia caregiver. Health Psychology, 26(5), 539-544.

McCurry, S. M., Logsdon, R. G., Teri, L., \& Vitiello, M. V. (2007). Sleep disturbances in caregivers of persons with dementia: Contributing factors and treatment implications. Sleep Medicine Reviews, 11(2), 143-153. https://doi.org/10.1016/j.smrv.2006.09.002

McEwen, B. S. (2006). Protective and damaging effects of stress mediators: Central role of the brain. Dialogues in Clinical Neuroscience, 8(4), 367-381.

Mosher, C. E., Adams, R. N., Helft, P. R., O'Neil, B. H., Shahda, S., Rattray, N. A., \& Champion, V. L. (2017). Positive changes among patients with advanced colorectal cancer and their family caregivers: A qualitative analysis. Psychology \& Health, 32(1), 94-109. https://doi.org/10 $.1080 / 08870446.2016 .1247839$

Mosher, C. E., Ott, M. A., Hanna, N., Jalal, S. I., \& Champion, V. L. (2017). Development of a symptom management intervention: Qualitative feedback from advanced lung cancer patients and their family caregivers. Cancer Nursing, 40(1), 66-75. https://doi.org/10.1097/ NCC. 0000000000000350

Moya-Albiol, L., Sanchis-Calatayud, M. V., Sariñana-González, P., András-García, S., Romero-Martínez, Á., \& González-Bono, E. (2011). Electrodermal activity in response to a set of mental tasks in caregivers of persons with autism spectrum disorders. European Psychiatry (Abstracts of the 19th European Congress of Psychiatry), 26(Suppl. 1), 1595.

Oh, Y. S. (2017). Communications with health professionals and psychological distress in family caregivers to cancer patients. A model based on stress-coping theory. Applied Nursing Research, 33, 5-9. https:// doi.org/10.1016/j.apnr.2016.09.008

Orr, S. P., \& Kaloupek, D. G. (1997). Psychophysiological assessment of posttraumatic stress disorder. In I. P. Wilson, \& T. M. Keane (Eds.), Assessing psychological trauma and PTSD (pp. 69-97). New York, NY: The Guilford Press.

Palatini, P. (2009). Elevated heart rate: A 'new' cardiovascular risk factor? Progress in Cardiovascular Diseases, 52(1), 1-5.

Palatini, P., \& Julius, S. (1997). Heart rate and the cardiovascular risk. Journal of Hypertension, 15(1), 3-17. https://doi. org/10.1097/00004872-199715010-00001

Pinquart, M., \& Sörensen, S. (2003). Differences between caregivers and non-caregivers in psychological health and physical health: A meta-analysis. Psychology and Aging, 18(2), 250-267. https://doi. org/10.1037/0882-7974.18.2.250

Powell, N. D., Sloan, E. K., Bailey, M. T., Arevalo, J. M., Miller, G. E., ... Chen, E., Cole, S.W. (2013). Social stress up-regulates inflammatory gene expression in the leukocyte transcriptome via $\beta$-adrenergic induction of myelopoiesis. Proceedings of the National Academy of Sciences of the United States of America, 110(41), 16574-16579. https://doi.org/10.1073/pnas.1310655110.
Pruchno, R. A., \& Potashnik, S. L. (1989). Caregiving spouses. Physical and mental health in perspective. Journal of the American Geriatrics Society, 37(8), 697-705.

Schrag, A., Hovris, A., Morley, D., Quinn, N., \& Jahanshahi, M. (2006). Caregiver burden in Parkinson's disease is closely associated with psychiatric symptoms, falls, and disability. Parkinsonism and Related Disorders, 12(1), 35-41. https://doi.org/10.1016/j. parkreldis.2005.06.011

Schulz, R., \& Beach, S. R. (1999). Caregiving as a risk factor for mortality: The Caregiver Health Effects Study. Journal of the American Medical Association, 282(23), 2215-2219. https://doi.org/10.1001/ jama.282.23.2215

Schulz, R., Newsom, J., Mittelmark, M., Burton, L., Hirsch, C., \& Jackson, S. (1997). Health effects of caregiving: The caregiver health effects study: An ancillary study of the Cardiovascular Health Study. Annals of Behavioral Medicine, 19(2), 110-116. https://doi.org/10.1007/ BF02883327

Schulz, R., O'Brien, A. T., Bookwala, J., \& Fleissner, K. (1995). Psychiatric and physical morbidity effects of dementia caregiving: Prevalence, correlates, and causes. Gerontologist, 35(6), 771-791. https://doi. org/10.1093/geront/35.6.771

Schulz, R., Visintainer, P., \& Williamson, G. M. (1990). Psychiatric and physical morbidity effects of caregiving. Journals of Gerontology: Series B: Psychological Sciences and Social Sciences, 45(5), P181-P191.

Sequeira, H., Hot, P., Silvert, L., \& Delplanque, S. (2009). Electrical autonomic correlates of emotion. International Journal of Psychophysiology, 71(1), 50-56. https://doi.org/10.1016/j.ijpsycho.2008.07.009

Shaw, W. S., Patterson, T. L., Semple, S. J., Dimsdale, J. E., Ziegler, M. G., \& Grant, I. (2003). Emotional expressiveness, hostility and blood pressure in a longitudinal cohort of Alzheimer caregivers. Journal of Psychosomatic Research, 54(4), 293-302. https://doi.org/10.1016/ S0022-3999(02)00412-9

Shaw, W. S., Patterson, T. L., Ziegler, M. G., Dimsdale, J. E., Semple, S. J., \& Grant, I. (1999). Accelerated risk of hypertensive blood pressure recordings among Alzheimer caregivers. Journal of Psychosomatic Research, 46(3), 215-217. https://doi.org/10.1016/ S0022-3999(98)00084-1

Sherwood, P. R., Given, B. A., Donovan, H., Baum, A., Given, C. W., Bender, C. M., \& Schulz, R. (2008). Guiding research in family care: A new approach to oncology caregiving. Psycho-Oncology, 17(10), 986-996. https://doi.org/10.1002/pon.1314

Shilling, V., Matthews, L., Jenkins, V., \& Fallowfield, L. (2016). Patientreported outcome measures for cancer caregivers: A systematic review. Quality of Life Research, 25(8), 1859-1876. https://doi. org/10.1007/s11136-016-1239-0

Soares, A. J. (2009). Variáveis psicossociais e reactividade emocional em cuidadores de dependentes de substâncias [Psychosocial variables and emotional reactivity in caregivers of substance dependents]. $\mathrm{PhD}$ thesis, University of Minho, Braga, Portugal.

Stampler, D. B., Wall, J. R., Cassisi, J. E., \& Davis, H. (1997). Marital satisfaction and psychophysiological responsiveness in spouses of patients with chronic pain. International Journal of Rehabilitation and Health, 3(3), 159-170. https://doi.org/10.1007/BF02766063

Stern, R. M., Ray, W. J., \& Quigley, K. S. (2001). Psychophysiological recording (2nd ed.). New York, NY: Oxford University Press.

Teixeira, R. J., \& Pereira, M. G. (2014). Psychological morbidity and autonomic reactivity to emotional stimulus in parental cancer: A study with adult children caregivers. European Journal of Cancer Care, 23(1), 129-139. https://doi.org/10.1111/ecc.12102

Teskereci, G., \& Kulakac, O. (2018). Life experiences of caregivers of women with gynaecological cancer: A mixed-methods systematic review. European Journal of Cancer Care, 27(1), e12456. https://doi. org/10.1111/ecc.12456

Thompson, R. L., Lewis, S. H., Murphy, M. R., Hale, J. M., Blackwell, P. H., Acton, G. J., \& Bonner, P. N. (2004). Are there sex differences 
in emotional and biological responses in spousal caregivers of patients with Alzheimer's disease? Biological Research for Nursing, 5(4), 319-330.

Treiber, F. A., Kamarck, T., Schneiderman, N., Sheffield, D., Kapuku, G., \& Taylor, T. (2003). Cardiovascular reactivity and development of preclinical and clinical disease states. Psychosomatic Medicine, 65(1), 46-62. https://doi.org/10.1097/00006842-200301000-00007

Uchino, B. N., Kiecolt-Glaser, J. K., \& Cacioppo, J. T. (1992). Age-related changes in cardiovascular response as a function of a chronic stressor and social support. Journal of Personality and Social Psychology, 63(5), 839-846. https://doi.org/10.1037/0022-3514.63.5.839

Vitaliano, P. P., Russo, J., Bailey, S. L., Young, H. M., \& McCann, B. S. (1993). Psychosocial factors associated with cardiovascular reactivity in older adults. Psychosomatic Medicine, 55(2), 164-177. https:// doi.org/10.1097/00006842-199303000-00005

Vitaliano, P. P., Scanlan, J. M., Zhang, J., Savage, M. V., Hirsch, I. B., \& Siegler, I. C. (2002). A path model of chronic stress, the metabolic syndrome, and coronary heart disease. Psychosomatic Medicine, 64(3), 418-435. https://doi.org/10.1097/00006842-200205000-00006

Vitaliano, P. P., Zhang, J., \& Scanlan, J. M. (2003). Is caregiving hazardous to one's physical health? A meta-analysis. Psychological Bulletin, 129(6), 946-972. https://doi.org/10.1037/0033-2909.129.6.946

Von Känel, R., Dimsdale, J. E., Mills, P. J., Ancoli-Israel, S., Patterson, T. L., Mausbach, B. T., \& Grant, I. (2006). Effect of Alzheimer caregiving stress and age on frailty markers interleukin-6, C-reactive protein, and D-dimer. Journals of Gerontology, 6(9), 963-969. https://doi. org/10.1093/gerona/61.9.963
Weitzner, M., Haley, W., \& Chen, H. (2000). The family caregiver of the older cancer patient. Hematology/Oncology Clinics of North America, 14(1), 269-281. https://doi.org/10.1016/S0889-8588(05)70288-4

Wilcox, S., Bopp, M., Wilson, D. K., Fulk, L. J., \& Hand, G. A. (2005). Race differences in cardiovascular and cortisol responses to an interpersonal challenge in women who are family caregivers. Ethnicity and Disease, 15(1), 17-24.

Yamaguchi, S., Cohen, S. R., \& Uza, M. (2016). Family caregiving in Japan: The influence of cultural constructs in the care of adults with cancer. Journal of Family Nursing, 22(3), 392-418. https://doi. org/10.1177/1074840716655530

Young, J., \& Snowden, A. (2017). A systematic review on the factors associated with positive experiences in carers of someone with cancer. European Journal of Cancer Care, 26(3), 1-18. https://doi.org/10.1111/ ecc.12544

How to cite this article: Teixeira RJ, Remondes-Costa S, Graça Pereira M, Brandão T. The impact of informal cancer caregiving: A literature review on psychophysiological studies. Eur J Cancer Care. 2019;28:e13042. https://doi.org/10.1111/ ecc.13042 